\title{
Challenges of the Aging Policies in Spain
}

\author{
Esther Sitges Macia ${ }^{1}$, María del Carmen Segura ${ }^{2}$, Enrique Conejero Paz $^{2}$ \\ ${ }^{1}$ Department of Health Psychology, Miguel Hernandez University of Elche, Elche, Spain \\ ${ }^{2}$ Department of Social and Human Sciences, Miguel Hernandez University of Elche, Elche, Spain
}

Email address:

esther.sitges@umh.es(E. S. Macia),maria.segurac@umh.es(M.del C. Segura),ecp@umh.es (E. C. Paz)

\section{To cite this article:}

Esther Sitges Macia, María del Carmen Segura, Enrique Conejero Paz. Challenges of the Aging Policies in Spain. Humanities and Social Sciences. Vol. 6, No. 5, 2018, pp. 143-149. doi: 10.11648/j.hss.20180605.12

Received: September 25, 2018; Accepted: October 25, 2018; Published: November 19, 2018

\begin{abstract}
Rapid population aging and the constant rise in human longevity represent one of the greatest social, cultural, economic and political transformations of today, especially in developed countries and, as a consequence of this, population aging has become one of the most important challenges for modern societies. In this regard, the World Health Organization said that due to the increase in life expectancy and the decline in the fertility rate, the proportion of people over 60 years of age is increasing more rapidly than any other age group in almost all countries. The aging of the population can be considered a success of public health policies and socio-economic development, but it also constitutes a challenge for society, which must adapt to this in order to improve the health and functional capacity of older people as well as their social participation and their security. For this reason, it is necessary to design political initiatives that are capable of responding to the different social demands but which, in turn, safeguard the rights of elderly people, focusing their activity on the concept of Active Aging, as proposed at the II World Assembly on Aging (2002). In Spain due to health policies and a healthier lifestyle has increased life expectancy, in this sense it is expected that Spain is the country in 2040 with this indicator highest in the world with a life expectancy of 85.8 years. On the other hand, the current design of the Spanish pension system is unsustainable in the long term since it has one of the lowest birth rates in the world. This document aims to deepen the debate on aging in Spain from a political and social perspective, based on the approach that active and healthy aging opens a window of opportunity for social and political innovation.
\end{abstract}

Keywords: Active Aging, Social Policy, Economy, Welfare, Retirement

\section{Regulatory, Political and Social Framework of Aging}

Population aging worldwide has become a global phenomenon [1] and, therefore, the way it is approached and studied also requires global policies and action that provide an effective response to this new social challenge [2]. It was not until 1948 that it was suggested that protection policies for the elderly should be designed on a worldwide level. That year, the UN General Assembly started to develop a series of measures directed at the elderly population as a result of the presentation by Argentina of a project called the Declaration of the Rights of the Elderly. Unfortunately, it never became an official document. Subsequently, in 1969, another attempt was made to institutionalize the rights of the elderly, it being Malta who asked the UN General Assembly to include in its program a topic entitled The question of the elderly and the old, but again, on this second occasion, a framework document with specific proposals failed to materialize.

It was not until 1978 that the UN approved the organization of a World Assembly on Aging, the I World Assembly on Aging being eventually held in Vienna in 1982, from which the first International Action Plan -IAP (1982)-, also called the Vienna Plan, emerged, which would serve as a guide for political and scientific thought for a large number of countries who set themselves the objective of achieving the highest possible levels of wellbeing for the adult elderly population [3].

The IAP (1982) included analysis, projections, programs, recommendations and policies to be applied internationally, regionally and nationally, promoting scientific research especially in developed countries through the creation of Gerontological Research Centers and a series of initiatives 
ranging from legislative developments and institutional engineering to the educational and cultural sphere. Among the general recommendations of the IAP, with regard to the issue in question, the special emphasis placed on a more active role for the elderly in society and their participation in decision-making on both a social and a political level, stands out. Furthermore, the IAP proposed for the first time that old negative stereotypes associated with aging be discarded [4], promoting the idea that a positive image of old age should begin to be adopted directed towards development and including specific recommendations in the areas of health and nutrition, housing and environment, family, social welfare, security, employment and education.

Despite these recommendations, the majority of European countries fundamentally directed their old age policies towards a care perspective, which helped to perpetuate stereotypes about old age. The UN did not have any body exclusively assigned to this issue, and so the task of monitoring it was allocated to the Center for Social Development and Humanitarian Affairs, but this was responsible for other issues and thus also unable to dedicate the time to it that it deserved.

Subsequently, in 1992, on the occasion of celebrating the tenth anniversary of the adoption of the Vienna International Action Plan, the UN adopted the Proclamation on Aging [5], whereby countries committed to supporting national initiatives directed, on the one hand, towards elderly women to ensure that they received the necessary support taking into account the great contribution they have made, and that they have been undervalued for so long. On the other hand, towards elderly men, encouraging them to broaden social, cultural and emotional skills they were unable to develop during the years prior to this stage. Provisions for guidelines and training required for basic care in the homes of the elderly were also made.

In 1994, the International Conference on Population and Development was held in Cairo, at which the economic and social consequences of population aging were addressed as a problem, but also as an opportunity, urging that aging policies be reconsidered in light of the principle that elderly population constitutes a valuable and important component of a society's human resources. Special note of support is made for the elderly in vulnerable circumstances as well as those with long-term support needs. The objectives proposed at said conference were:

(1) to increase, through appropriate measures, the autonomy of elderly people, as well as to create conditions that improve their quality of life and allows them to live and work independently in their own communities for as long as they can or wish to do so,

(2) to establish healthcare and economic and social security systems for elderly people, paying special attention to the needs of women and,

(3) to establish a social support system both in the official and non-official sphere that helps to increase the family capacities to take care of their elderly relatives.

Note is taken of the importance of inter- and intra- generational solidarity and support for the elderly through the protection and promotion of several generation families and the provision of long-term services and support. Emphasis was also placed on the need to increase the capacity of elderly people to fend for themselves and continue to participate in society, it being necessary to guarantee conditions so that they can live independent, healthy and productive lives and make use of the skills and aptitudes acquired throughout their lives for the society benefit. The need to recognize and promote the valuable contribution of the elderly to the family and society, especially in their role as volunteers and carers, and to articulate non-governmental organizations, and in the private sector, in furtherance of strengthening support and security systems as well as eliminating all forms of violence and discrimination, was another of the main objectives set at said Conference.

Subsequently, in 1995, a World Summit for Social Development was held in Copenhagen at which the quandary of elderly adults was again addressed, setting the objectives of:

a) recognition of, and respect for, the contribution of people of all ages for the construction of a harmonious society;

b) the promotion of dialog between generations;

c) the protection of elderly people;

d) the strengthening of family support systems;

e) social improvement for those people without a family;

f) access to social services and social security and,

g) advocating support measures to prevent poverty in this sector of the population.

As it can be seen, throughout the different world Summits and Conferences it was urged that age-related policies be developed in the firm belief about the importance of the elderly for social development. As stated by Belando \& Scarlet, aging policies should start from the premise that the elderly, constitute a group of the population that has a lot to offer society, and only from a real and profound approach to this reality effective policies, which will significantly reduce current costs and directly and indirectly benefit the rest of the population, could be developed [6]

Twenty years after the I World Assembly on Aging, in 2002, the II World Assembly on Aging was held in Madrid, which attempted to assess the work undertaken over the two previous decades and update the IAP. Two key documents were adopted: Policy Declaration and the Madrid International Action Plan on Aging 2002 (IAP 2002).

The IAP 2002 made reference to the need for a change in attitudes, policies and practices at all levels and in all sectors, to define the possibilities afforded by aging in the XXIst century. Globalizing a secure and dignified old age, whereby the elderly can continue participating in their respective societies as citizens with full rights, was set as an objective. A practical instrument to help those responsible for policy formulation was thus offered to consider the basic priorities associated not only with aging, but also with populations. The IAP 2002 proposed the following central themes [7]:

(1) The full realization of all human rights and 
fundamental freedoms;

(2) The aging of elderly people, making it possible for them to continue participating in the economic, political and social life of their societies, including through remunerated or voluntary employment;

(3) The opportunities for development, self-fulfillment and the wellbeing of the individual over the course of his/her life, including in old age, for example, through the opportunity to access learning during the whole of his/her life and taking part in the community, at the same time as recognizing that the elderly do not constitute a homogeneous group;

(4) The guarantee of the economic, social and cultural rights of the elderly, as well as their civil and political rights, and the elimination of all forms of violence and discrimination against elderly people;

(5) The commitment to, among other things, reaffirm the equality of sexes among the elderly, through the elimination of gender-related discrimination;

(6) The recognition of the importance they have for the social development of families and interdependence, solidarity and reciprocity between generations;

(7) Healthcare, support for, and the social protection of elderly people including preventive and rehabilitative healthcare;

(8) The promotion of an association between government, at all levels, civil society, private sector and the elderly themselves in the process of transforming the Action Plan into practical measures;

(9) The use of research, scientific knowledge and the potential of technology to consider, among other things, the individual, social and healthcare consequences of aging, especially in developed countries;

(10)The recognition of the situation of the elderly pertaining to indigenous populations, their special circumstances and the need to find the means so that they have an effective voice in decisions that directly affect them.

The IAP 2002 also made a series of recommendations about three main priority issues: elderly people and the development, promotion of health and wellbeing among the elderly, and the creation of a propitious and favorable environment for them [8].

In this sense, the WHO defines active aging [9] as an optimization process for health opportunities for the elderly adult, and comprises aspects of participation and security, for the purpose of improving the quality of life of people as they get older [10]

Important actions directed at the collective of elderly people are also being undertaken, such as, among others,

(1) The creation of Social protection systems, designed to provide protection against the risks and needs associated with social exclusion and aging, among others,

(2) The Age-Friendly Environments proposal, this being jointly undertaken with the WHO, an international effort to address social and environmental factors that contribute to an active and healthy old age. The AgeFriendly Environments program provides support to towns and communities to enable them to adapt to elderly people, addressing eight dimensions of their needs such as: the constructed environment, transport, housing, social participation, respect and social integration, civic participation and employment, communications, community support and health services.

(3) The creation, in the year 2000, of the European Innovation Partnership on Active and Healthy Aging (EIP), which proposed as an objective until the year 2020 , to increase life expectancy in good health by two years for Europeans, through long-term sustainable and effective healthcare and social systems, but also through increased competitiveness in the industry.

(4) The European Strategy 2000, known as the Lisbon Strategy, Lisbon Agenda or Lisbon Process. The latter being a European Union (EU) development plan whose objective was to convert the EU economy into the most competitive in the world by 2010 , based on knowledge and employment. A year later, the strategy was expanded with a sustainable development dimension and, in January 2004, new reinforcing priorities among which improving investment in networks and in knowhow stand out, to reinforce the competitiveness of industry and services, and promote the prolongation of an active life. The European Commission urged member states to adjust its social policies for the purpose of using resources as effectively as possible.

(5) In 2006, the Economic Policy Committee and the European Commission issued a report estimating that the active European population would fall below 48 million between 2010 and 2050; i.e., 16\% while its senior population would rise above 58 million.

(6) In 2008, the European Conference on protecting the dignity of elderly people and the prevention of abuse was held in Brussels, causing a debate between the member states that still remains ongoing.

(7) In 2012, the European Commission brought before the Council of the European Union the communication entitled Carrying out the Strategic Application Plan for European innovation cooperation on active and healthy aging. This talked about European innovation cooperation in the field of active and healthy aging (CIEEAS), setting increasing the life expectancy of EU citizens by two years until 2020 as a target, thus seeking a triple benefit for Europe by improving the elderly health and quality of life, improving the sustainability and the effectiveness of healthcare and dependency systems, as well as generating growth and market opportunities for businesses. The Strategic Application Plan focused on three pillars: prevention, detection and early diagnosis; healthcare and recovery; and active aging and autonomous living. Also considering health as an area of funding in the charge 
of the Regional Development European Fund and the European Social Fund, and urging member states to consider measures to promote active and healthy aging measures in their operational programs for the period from 2014 to 2020, which may help to achieve the objectives of the Structural Funds programs.

\section{The Aging Policies in Spain}

According to the Spanish Constitution of 1978, in its art. 50 , reference is made to the rights of the elderly and, specifically, to the right to a pension and services, such as health, housing, culture and leisure [11]. However, we do not find a plan as such on the policy to follow with regard to aging until 1988 when the National Gerontological Plan was developed for the purpose of drafting an integrated social policy in favor of elderly people [12]. This Plan was developed attending to the aforementioned article 50 of our Constitution, as well as to the directives indicated by the two World Assemblies on Aging. This Plan is a benchmark in integrated social policy for elderly people, and has marked a very important qualitative change in the ideological and philosophical principles that define the social care policies directed at this collective, as well as in the allocation of resources and development of specific programs for the elderly. In it, five areas of intervention with elderly people are specified:

a) Pensions

b) Health and healthcare

c) Social services

d) Culture and leisure

e) Participation

For said areas, the courses of action that should be developed are designed, as well as the objectives and measures to be adopted for the elderly population. Specifically, the objectives proposed are:

(1) To develop the system of non-contributory provisions directed at the over sixty-fives with insufficient economic resources, and to offer a pension supplement to the over eighties who have lost their personal autonomy.

(2) To improve minimum pensions and the rest of contributory pensions, guaranteeing its automatic revaluation according to the $\mathrm{CPI}$.

(3) To promote the elderly health and improve their physical, mental and social wellbeing.

(4) To guarantee, within the general framework of the National Health System, prevention and care for the elderly through appropriate primary and hospital care.

(5) To manage to bring social and healthcare services closer to the elderly, within a sectoral framework. To do so, a map of areas whereby said services are integrated and coordinated will be designed.

(6) To strengthen administrative structures for the development, coordination and equitable allocation of resources, as well as to guarantee the ongoing study, research and training on issues related to aging and old age.

(7) To offer social services suitable for responding to the needs of the elderly, improving, above all, the development of those which propitiate their selfautonomy, remaining in their own homes and harmony in their usual living environment.

(8) To increase awareness among the population about the social reality of an aging population and the psychosocial characteristics of the elderly, the appreciation and recognition of everyone for the values and cultural heritage of people who have reached an advanced age, as well as the participation and shared responsibility of the same in the development of social policy.

(9) To facilitate access for the elderly to cultural assets, and to encourage them to creatively use their leisure and free time in order to improve their quality of life and their capacity to feel useful.

(10)To extend the concept of democratic participation, so that society does really integrate the elderly and they get involved in all the social activities.

Subsequently, and for the purpose of attending to the new demands and needs of the elderly, in 1992, an updating of the National Gerontological Plan was begun, inspired by the principles of dignity, independence, self-realization, participation, healthcare and cooperation [13], and which set the year 2000 as its horizon. The main reasons that led to the realization of this Plan were:

(1) the new panorama in the organization of the Spanish Public Administrations,

(2) the new changing reality, as well as the challenges arising with respect to this collective of elderly people, and

(3) the recommendations of the International Plan of Action, resulting from the different recommendations and conclusions of the diverse summits and assemblies on aging held until that time.

According to the Assessment of the 1992-1997 Gerontological Plan Report, carried out and published by the Ministry for Employment and Social Affairs, General Secretariat for Social Affairs, IMSERSO (1 ${ }^{\text {st }}$ edition: 1999), the assessment was positive. All the proposals of the Plan regarding Pensions, Health and Healthcare, Social Services, Culture, Leisure and Participation, considered in a global way, had had a reasonable level of execution, even though it is true that certain deficits came to light which should be taken into account to achieve them in the future.

Then, the so-called Action plan for the Elderly 2003-2007 was developed in which the objectives proposed according to area of intervention were:

(1) Equal opportunities: promoting full autonomy and participation of the elderly in the Community, based on the principles of Active aging. As well as promoting policies to support elderly people in dependence situations.

(2) Cooperation: determining stable means of interadministrative cooperation, and extending those 
that already exist to achieve objectives dependent on global action. Also promoting the means of cooperation with, and participation in civil society. As well as implementing the most effective instruments of international cooperation in favor of the elderly.

(3) Specialized training: with the promotion of training and professionals qualification, as well as the implementation of training programs directed towards improving the training of non-professional carers.

(4) Information and research: Ensuring that the different social collectives are properly informed about the elderly from an integrated perspective. And offering to public and private entities that may be interested, through the Elderly People Observatory, integrated information about the different questions relating to aging. As well as the promotion of interdisciplinary gerontological research on a national and international level.

On February 27th 2014, at the headquarters of IMSERSO, the Proposals for the development of the European Union Council guidelines regarding elderly people document was presented. This document was drafted from the starting point of the guidelines laid out by the European Union with regard to active Aging [14] and is comprised by 19 guidelines based on three fundamental questions: What worries the elderly? Which issues do they want to rise with the public authorities and society? And, which action do they expect from these powers and from civil society?

After the public presentation of the document, in July 2014, IMSERSO organized three days of debate with the objective of receiving suggestions and generating innovative elements for their inclusion, so that these would serve as tools for dialog between administrations and civil society in order to generate optimal responses to the challenges presented by demographic aging, and to consolidate active and healthy aging as a fundamental part of a society social and personal development for all ages. As a result, 345 proposals were generated, although, as things stand, a specific approach has not been materialized from them yet.

However, in 2018, the Congress of Deputies, at the request of the Commission for Health and Social Services, approved a Non-Legislative Act related to promoting active aging policies, highlighting the need for public authorities to redefine their policies taking into account the progressive aging of each to "improve the quality of life of elderly people, to guarantee their participation in society, to prevent situations of dependence and to achieve true intergenerational solidarity, all of which guaranteeing the State of Wellbeing". Said proposition was drafted as follows:

"The Congress of Deputies urges the Government, within the framework of active aging policies and in collaboration with the Autonomous Communities, local bodies and social communication media, to:

1. Promote the realization of campaigns that divulgate a positive image of elderly people, casting negative stereotypes and discriminatory attitudes aside so as to guarantee equal rights for elderly people and making society aware of the value of active aging.

2. Include in the draft of the National Strategy for active aging and proper treatment of the elderly during the period 2018-2021 measures to sanction the abandonment of elderly people at social and healthcare centers.

3. Approve in the shortest possible term the National Strategy for Active Aging and proper treatment of the Elderly during the period 2018-2021.

\section{Discussion}

Government institutions cannot avoid demographic reality. In Spain, according to the National Statistics Institution (INE being the Spanish abbreviation), in January 2017, there were 8.7 million people over the age of sixty-five, which represents $18.8 \%$ of the total population ( 46.5 million). The difficulties and challenges represented by the accelerated population aging, make this phenomenon and its consequences transcend very diverse spheres.

According to Villar it is still necessary to study aging from its most negative consequences [15], or from the point of view of Subirats when he affirms that its necessary change in discourse to recognize the weaknesses is required, and that structural reforms of rights and provisions to be tackled [16]. This perspective must be kept in mind that, from the perspective of policies, the deployment of social policies focused on dependency care has predominated, which is a pattern that persists.

However, it is important to not forget that, within the group denominated as the elderly there are very diverse age groups, and a large number of them still have 10, 20 or even more years of life ahead of them without incapacitating illness. A broader vision of aging is therefore required because not all activities undertaken in old age have the same value, nor are individual circumstances identical across the whole collective. In this regard, the inclusion of the elderly in civic participation within the framework of generativity in old age, and better understanding the motivations, is required.

On the other hand, the approach that active and healthy aging opens a window of opportunity for social and political innovation [17]. In this sense, Subirats affirms that converting the system, very focused until now on medical pharmaceutical care, into one with more of a social healthcare and decentralized dynamic [18].

Along these lines, the promotion and visibility of the new forms of participation is essential, but also the empowerment of the elderly. In this sense, it is important to highlight the launch of global initiatives such as Aging 2.0 that is present in 20 countries, including Spain, and more than 50 cities around the world, this platform is focused on accelerating innovation and technological development in order to improve The lives of older people try to coordinate actions around the world to address 8 major challenges of aging [19].

Maybe the solution would be to look at it in a different way, not to see the elderly as an independent and 
unproductive collective of society, but rather as a part of it through everything they contribute and can continue to contribute. Someone outside the labor market can participate and socially participates by developing activities that he/she was unable to during his/her professional career. And because he/she now has the time, he/she has the experience to make a big contribution. Similarly, it is a new and profitable market that encompasses all countries [20]. Also, with regard to political activity, in Spain, for example, $6.9 \%$ of elderly are involved in political organizations [21].

And although it is true that active aging strategies exist on a regional and local level, little evaluation work has been done in this respect, and the economic crisis has meant that political action in this sense takes a back seat, without appreciating that responding to the great challenge of population growth in matters such as the retirement age, social provisions, health and promoting health prevention, using awareness campaigns, could, in turn, attenuate the effects of the economic crisis, given that the two issues are interrelated.

\section{Conclusion}

From a demographic point of view, humanity faces one of the greatest transformations in its history: a more populated, urban and longevity The world population will continue growing, until overcoming 8.500 million inhabitants in 2030 and, in addition, the proportion of those over 65 , up to $13 \%$ against the $8 \%$ current, especially in the economies advanced like Japan and the European Union.

Spain is increasingly aging it is predicted that by 2033 more than 3.4 million Spaniards will be 65 or more years old. At present, this group of people represents $19.2 \%$ of the population, while in 2033 it will represent $25.2 \%$ of the total. The society will continue aging and will exceed ten million octogenarian people in 2024. Thanks to health policies and a healthier lifestyle has increased life expectancy, in this sense it is expected that Spain is the country in 2040 with this indicator highest in the world with a life expectancy of 85.8 years. On the other hand, the current design of the pension system is unsustainable in the long term since Spain has one of the lowest birth rates in the world. For this reason, it is necessary to generate action proposals that allow the implementation of transversal policies of active aging to take advantage of the talent of this group for the benefit of society, and achieve an adequate intergenerational equilibrium. The challenges of aging, has yet to be adequately addressed.

\section{References}

[1] See Bernice L. Neugarten, Los significados de la edad. Barcelona: Herder, 1999.

[2] In this sense Juarez (1997) expresses this well: "population aging constitutes a new sociopolitical phenomenon that concerns developed societies", see Miguel Juarez, "Política social para personas mayores". In $\mathrm{M}^{\mathrm{a}}$ del Carmen Aleman \& Jorge Garces (coords), Política Social. Madrid: McGraw-Hill, 1997, pp. 447-478.
[3] In the Prologue to the IAP, countries were urged to consider it "as an integral part of the main regional, national and international programs and strategies formulated in response to important worldwide problems and needs. Its main targets are to strengthen the capacity of countries to effectively address the aging of their population, to attend to the concerns and special needs of the elderly and to promote a suitable international response to the problems of aging through measures for the establishment of the new world economic order and increasing international technical cooperation activities, particularly among developing countries. See http://www.un.org/es/comun/docs/?symbol=A/RES/47/5, accessed on 10th March, 2018.

[4] The tendency from the biological perspective to promote a negative view of aging is already a phase overcome, since there has been a transfer of the conventional definition of aging as a stage of decline and loss of cognitive function to an important historical change in the Psychology of aging, see P. B. Baltes; A. M. Freund, \& S. C. Li. "The psychological science of human ageing". In M. J. Johnson, V. L. Bengston, \& P. Coleman (Eds.), The Cambridge Handbook of Age and Ageing, Cambridge: Cambridge University Press, 2005, pp. 47-71.

[5] See http://www.un.org/es/comun/docs/?symbol=A/RES/47/5.

[6] See María R. Belando. \& Anne M. Sarlet, "Políticas de atención a la vejez en los sectores sanitario y social", in Jose Buendia (ed.), Gerontología y salud, perspectivas actuales. Madrid: Editorial Biblioteca Nueva, 1997, pp. 199-232.

[7] Report on the Second World Assembly on Aging, Madrid, from 8th to 12th April 2002. A/Conf.197/9.

[8] The former UN General Secretary, Kofi Anan, in his opening address, urged the 189 attending countries to build a proper society for everyone of all ages and highlighted that aging is now definitely not just a first world problem. What was of secondary importance in the XXth century is on the road to becoming a dominant theme in the XXIst century.

[9] At the end of the 20th century, a new paradigm of aging emerged that has been transformed according to its terminology such as successful aging (Rowe \& Kahn, 1987), good aging (Fries, 1989), healthy aging (WHO, 1990), competent aging (Fernandez-Ballesteros, 1996), or active aging (WHO, 2002). See John W. Rowe \& Robert L. Kahn. Human aging: Usual and successful. Science, 237, 1987, pp. 143-149; James F. Fries. Aging well. New Cork: Addison-Wesley, 1989; Rocio Fernandez-Ballesteros. Psicologia del envejecimiento: crecimiento y declive. Madrid: Universidad Autonoma de Madrid, 1996.

[10] See World Health Organisation. Active Aging. A Policy Framework. Geneva: World Health Organization, 2002, p. 12.

[11] In the Spanish constitution it is contemplated that Public authorities will guarantee, through adequate and regularly updated pensions, economic self-sufficiency for citizens during old age. Similarly, they will promote wellbeing through a social services system and will attend to specific health, housing, culture and leisure problems.

[12] The National Gerontological Plan was presented at the beginning of 1993, this Plan aimed to bring together the different policies on the elderly and improve social services. This program was agreed between the Central Administration and the different autonomous communities, and it included programs such as Residences, Home Help and Telecare. 
[13] See the Plan de acción para personas mayores 2003-2007 (Plan of action for elderly people 2003-2007). Ministry for Employment and Social Affairs (IMSERSO), 2003.

[14] See Proposals for the development of European Union Council guidelines, of December 6th 2012, regarding elderly people. Debate document, at http://www.imserso.es/imserso 01/mas informacion/agenda/2 014/febrero/IM_083029, accessed on 12th July, 2018.

[15] Feliciano Villar et al., Abordando la diversidad en el envejecimiento activo: Una propuesta de clasificación, Aula Abierta, 47(1), 2018, pp. 55-62.

[16] See Joan Subirats, Una concepción del envejecimiento abierta e inclusiva. Edad y ciudadanía. Aula Abierta, 47(1), 2018, pp 13-20.

[17] See Aitor Urrutia, Envejecimiento activo: un paradigma para comprender y gobernar. Aula Abierta, 47(1), 2018, p. 35.
[18] See Joan Subirats, Op. Cit, in this regard he also argues that the full insertion of the elderly in Spanish society it does not just happen to have guaranteed dignified living conditions, enjoy individual autonomy and see their personal and collective specificity recognized.

[19] See Aging 2.0 and the 8 challenges on aging: 1. Engagement and Purpose; 2. Financial Wellness; 3. Mobility and Movement; 4. Daily Living and Lifestyle; 5. Caregiving; 6. Care Coordination; 7. Brain Health; 8. End of Life, in https://www.aging2.com/about/, accessed on 17th June, 2017.

[20] See Aitor Urrutia, Op. Cit, pp. 29-36.

[21] See R. Serrat, et al. "Factors associated with Spanish older people's membership in political organizations: the role of active aging activities". European Journal of Ageing,1, 2015, pp.239-247. 